(3) While interviewing the parents of a patient, her father told me that as a soldier on $\mathrm{VE}$ day he found himself in the grounds of a German school. He picked up singed pages of a mathematics textbook presumably torn out to burn. The first question he deciphered began "The cost of maintaining one mentally defective individual per annum is $n$ marks".

(4) A newspaper article describes the execution in September 1995 of a "mentally retarded" man in Arkansas for murder.

As long as people with learning disabilities are regarded as disposable or a drain on the nation's purse, and staff working with learning disabled people are denigrated for doing so, there is little hope for the amelioration of their sufferings. But if professionals can set a lead in affording respect to these most vulnerable of individuals, perhaps one day they will be regarded as full citizens with equal human rights to ourselves.

ROSALIND E. BATES

Learning Disability Services, Ravensbourne NHS Trust

\section{Whose journal is it anyway}

Sir: Many colleagues have mentioned that on receiving their 'Yellow Journal' (British Journal of Psychiatry; BJP), they seem to get little further than reading the contents page. It has been our personal experience, in child psychiatry and psychotherapy, that there has often been little of interest among the academic papers in the journal. We therefore carried out a simple audit of the range of articles in the $B J P$ as compared to College Section membership figures.

We scanned the BJP from January 1993 to December 1994, and allocated each article to one of eight categories. These corresponded to the eight sections of the College: Child \& Adolescent; Forensic; Mental Handicap; Psychotherapy; Old Age; Social, Community \& Rehabilitation (SCR); Substance Misuse and General Adult Psychiatry. We compared the number of articles published in each category with the membership of each College Section and calculated the 'expected' number of articles that would occur if each section was proportionally represented.

The figures used for College Section Membership were published in the 1993-4 Annual Report, having been compiled after the rationalisation of Section Membership in which interested members were asked to affiliate by 'opting-in' to a maximum of two sections. Reviews, editorials, papers and short reports were included in the audit. A substantial majority were unequivocally

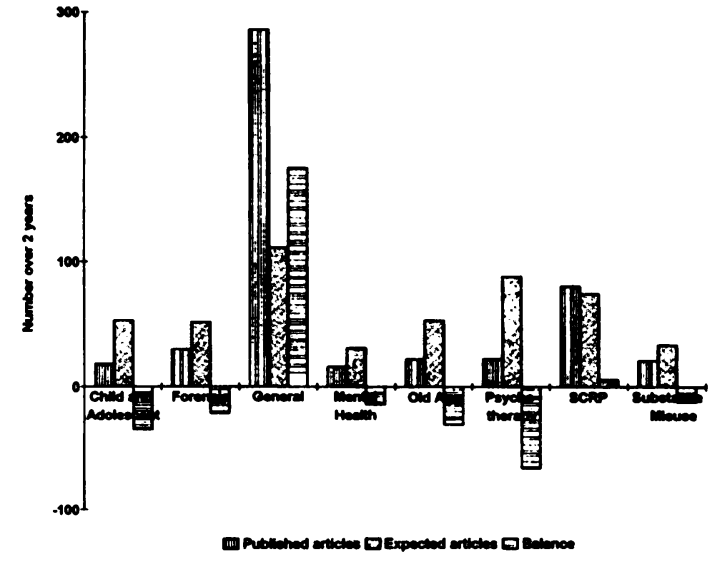

Fig. 1. British Joumal of Psychiatry: published and expected anticles

within a particular category. If there was doubt, allocation was according to the section to whom it would be of most interest and specialist categories were chosen in preference to general categories.

College Section membership is by definition a reflection of the balance of interest of College Members, and this is not well reflected in the numbers of articles currently being published in the BJP. Only SCR Psychiatry is close to being represented proportionally, with an average of just over three articles each month. Forensic, Mental Handicap, and Substance Misuse Psychiatry are under-represented, by less than one article too few per issue. Child \&Adolescent and Old Age Psychiatry had between one and two articles below the number expected. Psychotherapy had 66 articles fewer than expected over two years - between two and three per issue. In contrast, General Psychiatry had an average of about twelve articles each month: seven more than the expected five.

So whose journal is it anway? The British Journal of Psychiatry is clearly of more interest and relevance to some than others. We wonder how many would stop buying the journal if it were purchased separately from membership subscription, given the discrepancy between what College members are interested in and what is published. We suggest that a change of editorial policy could help the contents to be appreciated and processed somewhere between the letterbox and office shelf.

SAMUEL STEIN

Windmill Lodge, Ealing Hospital, Middlesex, UB1 3EU

REX HAIGH

West Berkshire Psychotherapy Department, 1 Princes Street, Reading. Berks RG1 4EG 